\title{
Spreading interest in particle physics among high-school students - what matters?
}

\author{
Sarah Zöchling ${ }^{a, b, *}$, Martin Hopf $^{a}$, Julia Woithe $^{b}$, and Sascha Schmeling ${ }^{b}$ \\ a University of Vienna, AECC Physics \\ Porzellangasse 4/2/2, 1090 Vienna, Austria \\ b CERN, \\ Esplanade des Particules 1, 1211 Geneva 23, Switzerland
}

E-mail: sarah.zochling@cern.ch, martin.hopf@univie.ac.at, julia.woithe@cern.ch, sascha.schmeling@cern.ch

Spreading interest in physics is crucial for the course and career choices of high-school students. When investigating interest in physics, previous studies focused on four aspects: interesting contents, contexts, tasks, and learning environments. Overall, physics education researchers agree that when trying to catch students' interest, context matters the most. However, previous studies did not include modern physics content areas such as particle physics. Moreover, they interpreted individual difference based on gender instead of students' self-concept. Thus, we examined what matters when spreading interest in particle physics among $9^{\text {th }}$ grade students. We adapted existing questionnaires assessing interest and self-concept to investigate a) which aspects of particle physics students are interested in and b) whether they differ in their interest profiles. We surveyed 99 German-speaking students in $9^{\text {th }}$ grade using an online questionnaire. The analysis revealed that particle physics is perceived as the most interesting when presented in a context, e.g., in relation to humans and nature. This is in line with previous findings about interest in classical physics. However, contrary to classical physics, analysis suggests that particle physics is equally interesting for all students.

40th International Conference on High Energy physics - ICHEP2020

July 28 - August 6, 2020

Prague, Czech Republic (virtual meeting) 


\section{Introduction}

In cooperation of the University of Vienna and CERN, we conduct a research project about the role of interesting contents and contexts in physics education. In particular, we analyse students' interest in modern physics contents such as particle physics.

\section{Research framework}

According to education research, spreading interest in physics among high-school students is crucial, since it plays an important role in their course and career choices [1]. Despite various efforts of making physics more interesting for students, their interest in physics as a school subject decreases over time [2].

The psychological construct "interest" is described by the "person-object-theory" developed by Krapp [3]. Here, a person's interest is always related to something (i.e. it is object-specific) [3]. Thus, the object of interest is crucial when investigating students' interest in physics. Previous studies focused on four aspects: a) interesting contents (e.g., mechanics), b) interesting contexts (e.g., biological), c) interesting tasks (e.g., conduct an experiment), and d) interesting learning environments (e.g., Science Centre).

In general, researchers have found that students' interest differs across different contents, contexts, tasks, or learning environments [2, 4]. For example, when focusing on tasks, it has been shown that 12-year-old students favour hands-on tasks, whereas older students are more interested in discussions $[2,5]$. However, apart from age, previous studies mainly interpreted gender differences $[2,4,6]$. For example, when focusing on contents, girls show a relatively low interest in motion and forces in comparison to boys' interest [6]. Nevertheless, there are a few contents (e.g., the Universe and its history [6]) and contexts (e.g., the possibility of life outside earth [4] or the human body [2]) that are extremely and equally interesting for all students. Moreover, previous studies agree that the context plays a special role. Indeed, the context of a learning activity is more important than its content, task, or learning environment when trying to catch interest $[2,4]$.

However, physics education researchers also examined which characteristics of a person influence interest and vice versa. Here, it has been shown that the physics-related self-concept correlates with interest in physics [7,8]. Broadly speaking, self-concept is one's perception of oneself [9]. When focusing on a certain subject such as physics, self-concept refers to one's beliefs in the own academic ability in this subject $[10,11]$.

Students differ in preferences and characteristics. Thus, they were categorised into different interest types in the framework of the "IPN Interessensstudie Physik" [2]. Here, the focus was on gender for distinguishing between the different interest types. Still, when characterizing the students within each type, information about their physics-related self-concept was provided as well [12]. In principle, a differentiation was made between students who are generally and highly interested in the broad field of physics, and those who are only interested in physics related to humans and nature, applications and society [13]. The former group consists mainly of boys and/or students with positive physics-related self-concept, whereas the latter group consists mainly of girls and/or students with negative physics-related self-concept [13].

\section{Research interest}

Modern physics contents such as particle physics have not been included in previous studies. Furthermore, the focus has not been on physics-related self-concept but rather on gender issues 
of physics education. Therefore, in the framework of this research project, we conduct a new study to examine, into which different types of interest in physics German-speaking $9^{\text {th }}$ grade students (i.e. aged 15 to 16 years) can be categorised, while ...

- comparing modern and classical physics contents (namely particle physics and mechanics) and

- focusing on self-concept as clustering variable rather than on gender.

We hypothesise that the interest types described by Sievers [13] are still valid for today's students, and for modern as well as classical physics contents. In addition, we hypothesise that the interest types are described better, when using self-concept instead of gender as clustering variable, as the data analysed in the framework of the "IPN Interessensstudie Physik" suggest [2]. Finally, we hypothesise that modern physics contents are more interesting for students than classical ones.

\section{Research design}

The research is conducted in the framework of "S'Cool LAB", CERN's Physics Education Research facility. Usually, high-school students and teachers contribute to research projects by taking part in hands-on and minds-on workshops on-site at CERN. However, in this study, we use an online questionnaire for surveying students' interest in physics because CERN was closed for visitors due to COVID-19. We modelled our questionnaire on the "IPN Interessensstudie Physik" questionnaire, which examined interest in eight different physics content areas [2]. The IPN questionnaire consists of an introductory text as well as 11 interest items for each content area. Each item represents a category (i.e. a certain combination of context and task). Five of these 11 item categories are listed in Table 1 (middle column). The students express their interest in each item on a 5-point Likert-scale ranging from "My interest in it is ..." very high $(=1)$ to very low $(=5)$.

\begin{tabular}{|c|l|l|}
\hline$\#$ & Item category & Exemplary item \\
\hline 2 & $\begin{array}{l}\text { Learning more about natural phe- } \\
\text { nomena }\end{array}$ & $\begin{array}{l}\text { Learning more about how particle physics helps to } \\
\text { understand northern lights }\end{array}$ \\
\hline 4 & $\begin{array}{l}\text { Learning more about qualitative } \\
\text { physics }\end{array}$ & $\begin{array}{l}\text { Learning more about which interaction binds to- } \\
\text { gether the elementary particles in the nucleus space }\end{array}$ \\
\hline 7 & $\begin{array}{l}\text { Getting insight into jobs related to } \\
\text { humans }\end{array}$ & $\begin{array}{l}\text { Getting insight into the workflow in a medical diag- } \\
\text { nostic centre }\end{array}$ \\
\hline 8 & Constructing technical devices & Building a particle detector out of daily life objects \\
\hline 11 & $\begin{array}{l}\text { Discussing the societal relevance } \\
\text { of physics }\end{array}$ & $\begin{array}{l}\text { Discussing why research in particle physics is im- } \\
\text { portant for our society }\end{array}$ \\
\hline
\end{tabular}

Table 1: Five exemplary item categories of the "IPN Interessensstudie" $[8,14]$ and one exemplary item for each category developed for this study about interest in particle physics

In the framework of this research project, we developed a questionnaire about interest in particle physics. Thus, we created an introductory text about particle physics and at least three items per item category according to the "IPN Interessenstudie Physik". Exemplary items about the interest in particle physics are listed in Table 1 (right column).

Then, we conducted virtual one-on-one interviews with nine students ( 5 female, 4 male) using a think-aloud protocol according to Sandmann [15] to test the comprehensibility of the text and the items. Each interview took between half an hour and an hour, depending on the student. 
The interviews were audio-recorded and transcribed. Then, we conducted a content analysis of the transcripts. As a result, we rephrased and shortened parts of the introductory text. Moreover, we selected three items per item category. Afterwards, we conducted think-aloud interviews with seven students (4 female, 3 male) to check the comprehensibility of the revised questionnaire. Content analysis of the transcripts of the second round of interviews confirmed that no further revision of the text nor of the items is necessary.

Afterwards, we implemented the developed introductory text about particle physics and the 33 corresponding interest items in an online questionnaire. Moreover, items about the personal background as well as the physics-related self-concept of the students were included. The latter items were divided into two categories, see Table 2. In particular, six self-efficacy items adapted from PISA 2006 represented the first category [16]. However, whereas in PISA2006 self-efficacy data with respect to natural sciences were collected, the focus of this study was on physics-related self-efficacy. Moreover, four items about perceived recognition adapted from Kalender et al. [7] represented the second category of self-concept items.

\begin{tabular}{|c|l|l|}
\hline$\#$ & Item category & Exemplary item \\
\hline 1 & Self-efficacy & Physics topics are easy for me. \\
\hline 2 & Perceived recognition & My parents think I am good in physics. \\
\hline
\end{tabular}

Table 2: The two item categories about students' physics-related self-concept and one exemplary item for each category

\section{Participants}

We sent out an e-mail invitation to participate in the study to several randomly selected teachers in Austria and Germany. As a result, the questionnaire was filled in by one class each from Vienna, Graz, and a city close to Munich as well as individual students from three schools in Tyrol. The latter ones have received the link to the questionnaire from their teachers. In total, 99 students (57 female, 41 male, 1 not specified) participated in the study.

\section{Analysis}

We chose a mixed-Rasch approach to analyse the data because it combines the plus-sides of two analysis methods, in particular, of latent class analysis and Rasch analysis [17]. In latent class analysis, a latent, qualitative variable is assigned to every person according to which he or she is categorised into a class [13]. In our study, this qualitative variable reflects the type of interest of a student. At the same time, Rasch analysis is conducted within each class. Here, the result is a quantitative parameter for each person [13]. In our study, this quantitative parameter reflects the degree of interest of a student. This means that within a type of interest, persons can differ in their degree of interest.

We compared the results of the mixed-Rasch analysis for three different models, from only one interest type (i.e. the sample cannot be divided into different interest types) to a classification into three interest types. As a criterion for model validity, we used the BIC value since previous studies suggest that it is the most reliable when conducting mixed-Rasch analysis [13, 18, 19]. Here, a smaller BIC value indicates that the corresponding model describes the collected data better than other models with higher BIC values [13, 18, 19]. 


\section{7. $\quad$ Results}

The BIC values of the three calculated models are listed in Table 3. Indeed, the BIC value of the 1-class-model is the smallest, which means that the 1-class-model describes the data the best. Consequently, the students of this sample cannot be categorised into different interest types.

The Rasch analysis provides information about the participants' degree of interest as well as the interestingness of the items. The items rated as the most interesting present particle physics with relation to humans and nature, applications and societal relevance. For example, the three most interesting items are "Learning more about how to treat diseases using particle accelerators", "Learning more about how particle physics contributes to a better understanding of the big bang", and "Learning more about how to detect smuggled weapons in a container using particle detectors". In contrast, items rated as the least interesting present qualitative and quantitative particle physics without context. For example, the three least interesting items are "Learning more about which interaction binds together the elementary particles in the nucleus space", "Learning more about the masses of different elementary particles in comparison to each other", and "Calculating the masses of different elementary particles since they cannot be weighed".

\begin{tabular}{|r|c|c|c|}
\hline Number of classes & $\mathbf{1}$ & $\mathbf{2}$ & $\mathbf{3}$ \\
\hline BIC & 9168 & 9998 & 10996 \\
\hline
\end{tabular}

Table 3: BIC values of the three calculated models

\section{Discussion}

In contrast to the initial hypothesis, students of this sample cannot be categorised into different types of interest in particle physics. However, there are several limitations to this study that could explain this unexpected finding. First, in general, students ranked their interest related to particle physics relatively high, which could result in an oversaturation of the scale. Second, the sample size was relatively small and might not allow to generalise the results of the mixedRasch models. Third, the sample was not randomised but partially self-selected. Therefore, the sample might be biased towards students and/or teachers with a particularly high interest in particle physics. However, the most promising explanation from a particle physics point of view is that the content area particle physics is indeed equally interesting for all students.

Furthermore, the ranking of the interestingness of items is consistent with previous studies, which showed that the context is the key factor for catching interest in physics. Hence, even when trying to spread interest in particle physics, it is crucial to highlight its relation to humans and nature, as well as its applications and relevance for society.

\section{Next steps}

To overcome the above-mentioned limitations of this study, a cross-cohort study with 500 German-speaking $9^{\text {th }}$ grade students (i.e. aged 15 to 16 years) will be conducted. In the planned study, we will compare the interest in two content areas, particle physics and mechanics. Regarding the content area particle physics, we will use the created introduction text as well as 11 corresponding interest items (i.e. one item per item category). Regarding the content area mechanics we will use the corresponding part of the "IPN Interessensstudie Physik". Hence, we will be able to compare the interest of today's students with the data collected in the 80ies. In addition, we will present students with a new introduction text about mechanics. This will enable us to evaluate the influence of the introduction text on the expressed interest. 


\section{References}

[1] Blankenburg, J. S., Höffler, T. N., \& Parchmann, I. (2016). Fostering today what is needed tomorrow: Investigating students' interest in science. Science education, 100(2), 364-391.

[2] Häußler, P., Lehrke, M., \& Hoffmann, L. (1998). Die IPN-Interessenstudie Physik. Kiel: IPN.

[3] Krapp, A. (2002). Structural and dynamic aspects of interest development: theoretical considerations from an ontogenetic perspective. Learning and Instruction, 12, 409. doi:10.1016/S09594752(01)00011-1

[4] Sjøberg, S., \& Schreiner, C. (2012). Results and Perspectives from the ROSE Project: Attitudinal aspects of young people and science in a comparative perspective. In Science Education Research and Practice in Europe (pp. 203-236): Brill Sense.

[5] Swarat, S., Ortony, A., \& Revelle, W. (2012). Activity matters: Understanding student interest in school science. Journal of Research in Science Teaching, 49(4), 515-537.

[6] OECD. (2016). PISA 2015 Results (Volume I): Excellence and Equity in Education. Paris: OECD Publishing

[7] Kalender, Y., Marshman, E., Schunn, C., Nokes-Malach, T., \& Singh, C. (2019). Why female science, technology, engineering, and mathematics majors do not identify with physics: They do not think others see them that way. Physical Review Physics Education Research, 15(2), 020148.

[8] Rost, J., Sievers, K., Häußler, P., Hoffmann, L., \& Langeheine, R. (1999). Struktur und Veränderung des Interesses an Physik bei Schülern der 6. bis 10. Klassenstufe. Zeitschrift für Entwicklungspsychologie und pädagogische Psychologie, 31(1), 18-31. doi:10.1026//00498637.31.1.18

[9] Shavelson, R. J., Hubner, J. J., \& Stanton, G. C. (1976). Self-concept: Validation of construct interpretations. Review of educational research 46(3), 407-441.

[10] Marsh, H. (1990). The structure of academic self-concept: The Marsh/Shavelson model. Journal of educational psychology, 82(4), 623.

[11] OECD. (2007). PISA 2006: Science Competencies for Tomorrow's World. Volume 1, Analysis: OECD.

[12] Häußler, P., Hoffman, L., Langeheine, R., Rost, J., \& Sievers, K. (1998). A typology of students' interest in physics and the distribution of gender and age within each type. International Journal of Science Education, 20(2), 223-238. doi:10.1080/0950069980200207

[13] Sievers, K. (1999). Struktur und Veränderung von Physikinteressen bei Jugendlichen. (Doctoral), Universität Kiel, Kiel.

[14] Häußler, P., Hoffmann, L., Langeheine, R., Rost, J., \& Sievers, K. (1996). Qualitative Unterschiede im Interesse an Physik und Konsequenzen für den Physikunterricht. Zeitschrift für die Didaktik der Naturwissenschaften, 2(3), 57-69.

[15] Sandmann, A. (2014). Lautes Denken-die Analyse von Denk-, Lern-und Problemlöseprozessen. In Methoden in der naturwissenschaftsdidaktischen Forschung (pp. 179-188). Berlin, Heidelberg: Springer.

[16] Frey, A., Taskinen, P., \& Schütte, K. (2009). PISA 2006 Skalenhandbuch: Dokumentation der Erhebungsinstrumente: Waxmann Verlag.

[17] von Davier, M., \& Rost, J. (1995). Polytomous mixed Rasch models. In Rasch models (pp. 371379): Springer.

[18] Preinerstorfer, D., \& Formann, A. K. (2012). Parameter recovery and model selection in mixed Rasch models. British Journal of Mathematical and Statistical Psychology, 65(2), 251-262. doi:10.1111/j.2044-8317.2011.02020.x

[19] Sen, S. (2018). Spurious Latent Class Problem in the Mixed Rasch Model: A Comparison of Three Maximum Likelihood Estimation Methods under Different Ability Distributions. International Journal of Testing, 18(1), 71-100. doi:10.1080/15305058.2017.1312408 